\title{
Defects and Incompatibilities of Pipes Manufactured by Pilgrim Method
}

\author{
Jesica Biś, Bartosz Koczurkiewicz \\ Czestochowa University of Technology, Poland \\ Igor Mazur \\ Lipetsk State Technical University, Russian Federation
}

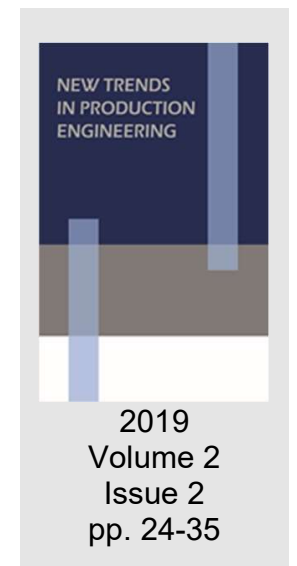

Date of submission to the Editor: 09/2019

Date of acceptance by the Editor: 11/2019

\section{INTRODUCTION}

The increase in the quality requirements for the pipes produced and the everincreasing competition exerts on producers the need to reduce production costs, while increasing the efficiency of the process. One of the cost reduction factors is the reduction of the number of defects by early detection and, if possible, the removal of non-conformities. Incompatibility is a defect that can be removed in accordance with the performance standard that does not cause defects (Norma API). The defect, on the other hand, is imperfection (defect) that is so important that it is the basis for the failure of the product or its part based on the criteria set out in the performance standards.

In pipe manufacturing processes, defects and batch inconsistencies can be distinguished, which arise in the steelworks during metal solidification and roll forming in the course of metal processing. The defect may also arise as a result of removing steel material or result from milling defects.

The paper presents the analysis of the process of quality control of pipes manufactured using the pilgrim method on the basis of real process data. The analysis involved 1070 pieces of ingots from 11 different melts constituting the charge for rolling pipes. At various stages of production, discrepancies and defects were revealed, which were caused by metallurgical or technological defects associated with rolling pipes. The total amount of discrepancies and defects eliminated 168 pieces of finished pipes. The aim of the work is to show that by means of appropriately selected methods of eliminating imperfections, it is possible to increase the efficiency of the manufacturing process.

\section{DEFECTS AND INCOMPATIBILITIES CREATED BEFORE THE ROLLING PROCESS}

Incompatibilities of the material for rolling process have a significant impact on the formation of material defects in the produced pipes. Early diagnostics of defects allows their removal or elimination at the initial stage of production, resulting in improved process efficiency. 
Input material for production of pipes to is evaluated a quality control immediately after its production in the steelworks. Before starting the rolling process, the quality verification is conducted by checking the condition of the surface and the compatibility of the smelting analysis with the order.

It is necessary to distinguish defects and incompatibilities created in the steelworks during solidification of metal and others, which are created during rolling mills as a result of errors in the production process. According to the author of the work (Kudliński, 2006), it can be divided into two basic groups:

- defects and shape incompatibilities (geometric),

- material defects.

In (Kudliński, 2006) material defects are defined:

- material discontinuities, voids in the material caused by the burning out of contaminants by degassing during steel solidification,

- non-metallic inclusions, steel contamination in the form of fragments of refractory

- metallurgical devices congealed in the material during casting and solidification,

- longitudinal and transverse cracks, resulting from stresses during solidification,

- unfolding, curling of the metal on the surface of the ingot resulting from the settling of slag on the walls of the mold,

- uncomfortable, breaks on the outer layer of the ingot pointing towards its axis. Incompatibilities of the batch material have a significant impact on the formation of defects and material incompatibilities in the manufactured pipes. Their early detection and elimination decreases the loss of the rolling mill. The control processes are made by the quality control services of the steelworks, but before the rolling process starts quality control services are working too (Dobrzański, 1996, Pavlov \& Erpalov, 2019).

It is allowed to occur on the surface of the ingots unflatten, grooves, partial melting and carriers characteristic for degassing processes. At the ends of the ingots, it is allowed to have a characteristic shape for cutting ingots with gasoxygen burners. In the axial zone, small cracks, looseness and porosity are acceptable. Defects and incompatibilities material due to the place of retention can be divided into surface and internal as well as defects in chemical composition. On the outer surface must be free from defects of the ingot in the form:

- longitudinal and hanger crack (Fig. 1),

- hanger crack of the corner (Fig. 2),

- trace shrink hole. 


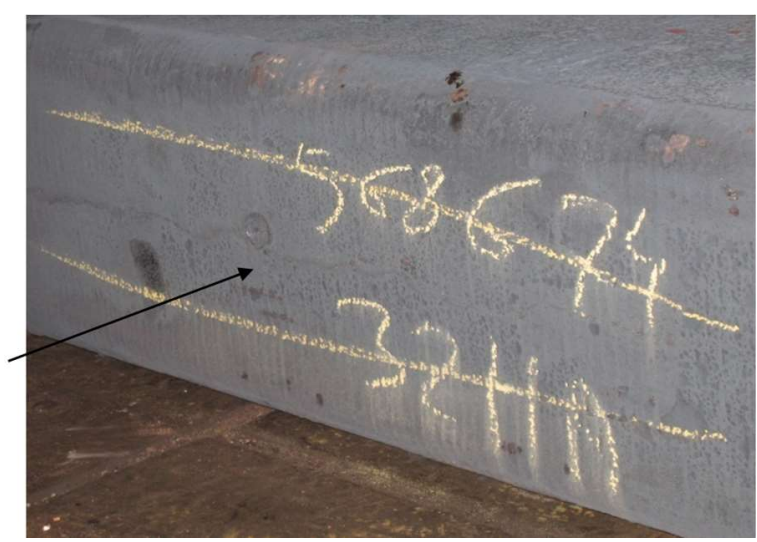

Fig. 1 Longitudinal crack ingot

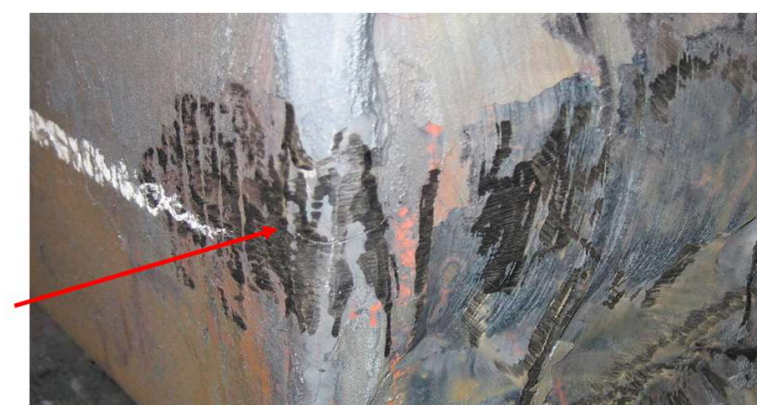

Fig. 2 Cracked corner

\section{DEFECTS AND INCOMPATIBILITIES CREATED DURING THE ROLLING PROCESS}

One of the most widespread methods of pipe rolling is the pilgrim method. The production by this method carbon and alloy steel and special alloys pipes with a wide dimensional range of external diameters $D=159-710 \mathrm{~mm}$ and wall thicknesses $\mathrm{g}=5.0-120 \mathrm{~mm}$. This method is economically viable with a flexible production program for small One of the most widespread methods of pipe rolling is the pilgrim method, which allows the production of pipes made of carbon and alloy steel and special alloys with a wide dimensional range of external diameters $D=159-710 \mathrm{~mm}$ and wall thicknesses $\mathrm{g}=5.0-120 \mathrm{~mm}$. This method is economically viable with a flexible production program for small batches of tubes for diameters $D>244.5 \mathrm{~mm}$. The first pilgrim mill was built in 1890 in the Czech Republic. The technological process of rolling seamless tubes in a pilgrim mill can be divided into stages (Knapiński et al., 1999):

- piercing in the presses of ingots with thick-walled sleeves with bottom,

- alongation rolling,

- rolling in a pilgrim mill,

- finishing rolling in rolling mills with tensioning or calibrating.

The produced pipe is subjected to the next verification process in order to make the product compatible with the order. Defects and incompatibilities of finished products are related to the material and shape. Material defects are included (Murcki \& O'Donnel, 1955):

- surface:

- scales on the outer and inner surface, 
- cracks on the outer or inner surface,

- crumples on the external or internal surface,

- features,

- burrs and creases,

- other mechanical damage,

- inside:

- non-metallic inclusions,

- cracks in the inside of the material,

- delamination,

- dirt.

The abovementioned irregularities may result from poor quality of the delivered material (steel defect) or imperfections in the rolling process. Figure 3 presents an example of a steel- based defect a shell, i.e. thin rolled metal layers, partly connected to the surface of the pipe.

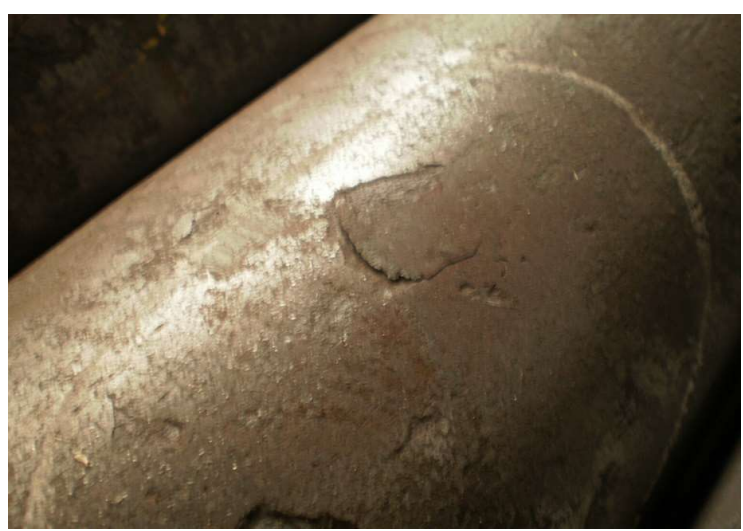

Fig. 3 The scale on the outer surface

This irregularity arises in the rolling process related to the intensive reduction of the cross-section, but its cause is a steel defect most often found inside the metal.

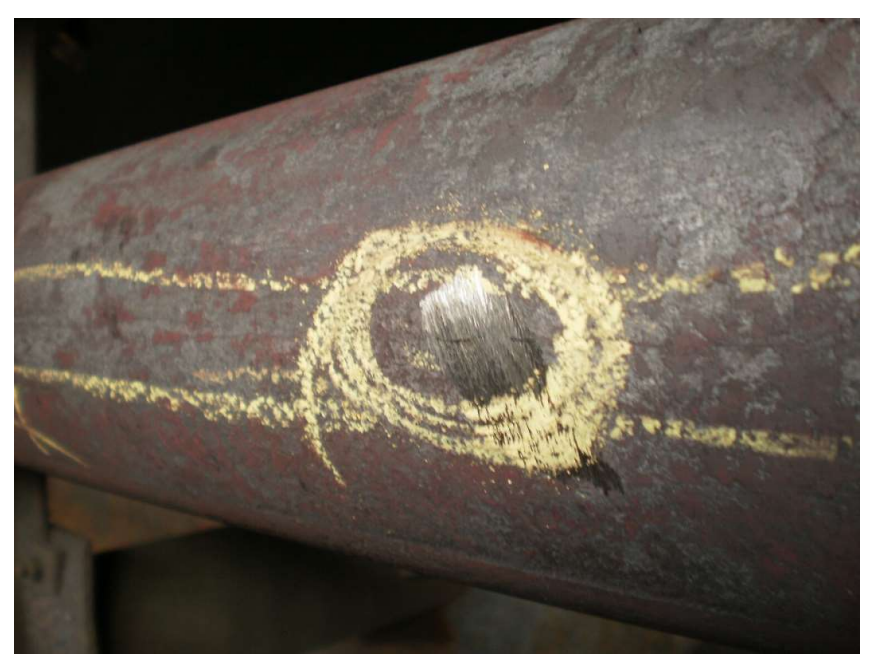

Fig. 4 Crack on the outer surface 
Figure 4 shows another incompatibility, crack. It may be both a steel-based defect (discontinuity of the material formed in the steelmaking process, but revealing only after rolling), and rolling resulting from, for example, under heating of the stock or resulting from finishing operations, e.g. high hardening stresses (Hoderny \& Korek, 1976, Shen et al., 2016, Utsunomiya et al., 2014).

Other defects of rolling process may also include, too low strength properties. Such defects may be removed by subjecting a pipes to heat treatment or reclassification of the material to another strength group (Przybyłowicz, 1999).

Surface defects are usually the result of defects in the mill equipment or other plant equipment and failure to follow the technological instructions (Nioi et al., 2017). The most common defects in shape are:

- incorrect outer or inner diameter,

- ovality,

- incorrect wall thickness,

- differentiating wall thickness,

- incorrect straightness,

- incorrect length,

- incorrect length after removing the defect,

- scratches, burrs and other mechanical damage,

- defects in the shape and dimensions of pipes with mechanically machined ends.

Incorrect outer diameter is related to exceeding the permissible difference between the outside diameter of the pipe, measured anywhere on the length and circumference, and the nominal diameter. The reason for such a defect is usually the failure to maintain the rolling parameters, the wear of work rolls or the misalignment of the calibration rolls. Incorrect internal diameter results from exceeding the permissible deviation between the inside diameter of the pipe, measured at the ends or determined on the basis of measurements of the outside diameter and wall thickness, anywhere on the length and circumference of the pipe, and the nominal internal diameter. The reason for the incorrect internal diameter may be the failure to maintain the rolling parameters, the worn roller rod, the poor calibration causing too large a reduction in the outside diameter or the curvature of the pipe (Luo et al., 2014, Nioi et al., 2019). Removal of the defect is possible by grinding the internal surface with a pneumatic or a cutting machine, sometimes straightening. The control is carried out with a twoborder template after each stage of changing the shape of the pipe. Too large outer diameter can be corrected by re-rolling on a calibrating roll or changing the size to a smaller diameter (reclassifying to another pipe dimension or other purpose). Checking the internal diameter is done by means of a control rod inserted into the inside with defined dimensions and pushing it with compressed air (Gulajew, 1958, Penkała, 2017, Wang et al., 2014).

Another incompatibility is the ovality of exceeding the permissible difference between the maximum and minimum pipe diameter, measured in one crosssection, anywhere and the length of the pipe. The reason for the ovality may be, 
among others: failure to maintain rolling parameters, non-centric piercing process, poor calibration or used un calibrating rolls, and its removal is possible by recalibration.

Incorrect wall thickness is the exceeding of the permissible difference between the wall thickness of the pipe, measured anywhere on the length and circumference, and the nominal thickness. The reason for this incompatibility is: failure to maintain rolling parameters, a worn rolling pin, worn work rolls or lack of proper control of the rolling process. The thickness of the wall is controlled by a clock device called a wall screen at the ends of the pipe. The thickness of the wall is also controlled by ultrasonic testing (Kazanecki, 2003).

Differentiating wall thickness (Fig. 5) is a typical incompatibility of the shape of a pilgrim mill and on the visible difference in wall thickness on the pipe crosssection sometimes exceeding its permitted tolerances.

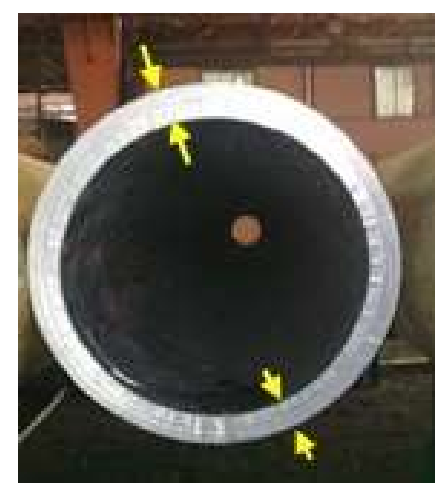

Fig. 5 A pipe with a distinctly different wall $\left(t_{1}>t_{2}\right)$

Because for the costumers, the product's straightness is important, apart from the diameter and wall thickness, determined by the deflection arrow, measured (Fig. 6) along the pipe, by comparing with a simple measure (or strained line) of a given length at any point along the length and circumference of the tube.

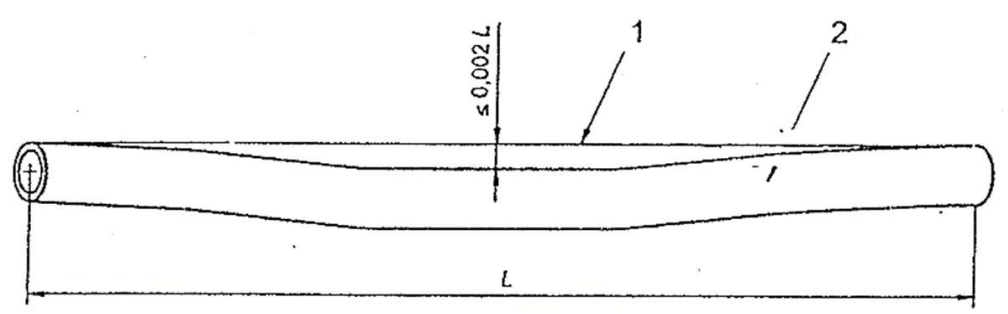

Fig. 6 Measurement of the straightness with a string:

1 - pulled string, 2 - lines

The reason for the curvature is usually: too high or too low straightening temperature, failure to maintain straightening parameters. Differential wall thickness pipe can also cause it to bend when cooling due to uneven material shrinkage. The removal of this defect occurs by re-straightening or cutting off the crooked end, unless it disqualifies the pipes for further production.

Incorrect length is exceeding the permissible maximum length or minimum length. The most common reason for the occurrence of the wrong minimum 
length is the need to cut a some length of pipe with rolling defect. It is measured manually by measuring tape or on a device for measuring length and weight.

Other defects of rolling include (Dobrzański, 1996): incorrect mechanical properties of the material, failure or exceeding mechanical properties e.g. yield strength, tensile strength, elongation, impact resistance, hardness. Such defects may be removed by subjecting a pipes to heat treatment or reclassification of the material to another strength group. However, in practice the most frequently used heat treatment.

In the pipe finishing stage there is a possibility of appearance of defects and non-conformities regarding:

- shape and dimensions of pipes with machined ends,

- incorrect marking,

- incorrect machine tightening of the connector,

- incorrect anti-corrosion protection,

- negative leak test result.

Shape defects are removed by cutting and re-machining.

Some of them are removable by cutting and re-machining, but some disqualify the product for sale and increase the cost of production. Early detection incompatibility in batch materials, semi-finished products and products will enable improvement of product quality, improvement of process liquidity, avoiding costs related to re-processing of the material, and above all, reduction of enterprise costs and its development (Dwivedi et al., 2017, Morioka et al., 1997).

\section{ANALYSIS}

The analysis of the occurrence of defects in the production of seamless tubes was based on real industrial data. Analyzed 1070 ingots from which 704.14 tons of ready-made pipes manufactured using the pilgrim method were rolled out. Defects and incompatibilities were determined and defined on the basis of studies including:

- smelting analysis,

- quality control of the charge after delivery by the manufacturer,

- batch quality control after heating in a rotary hearth furnace,

- piercing process,

- rolling process on an extension mill,

- rolling process on a pilgrim mill,

- heat treatment process,

- calibration process,

- initial acceptance,

- analysis of strength and non-destructive tests,

- finishing and final treatments.

The information (Table 1) presents a quantitative summary of the pipes remaining in the different stages of production, defects and incompatibilities by individual melts. 
Table 1 Quantity comparison of pipes during the entire production process

\begin{tabular}{l} 
Table 1 Quantity comparison of pipes during the entire production process \\
\begin{tabular}{|c|c|c|c|c|c|c|c|c|c|c|c|c|c|c|c|c|}
\hline \multicolumn{10}{|c|}{ Quantity comparison } \\
\hline
\end{tabular} \\
\hline
\end{tabular}

The analysis shows that in 10 out of 11 casts defects were found, only in one batch of material no irregularities were observed. The research allowed to determine the type of defects. The quality control of the batch indicated that 5 ingots were inconsistent with the order. As a result of the analysis 14 defective ingots with steel defects were obtained and excluded from production after the piercing process. Another 4 pieces have been withdrawn from production due to defects revealed after rolling in a rolling mill. After the heating process in the rotary furnace no discrepancies or defects were found. Initial acceptance after heat treatment and calibration reduced the number of tubes produced by 43 items, of which 15 were reclassified, and 28 were scrapped. The next production stage revealed inconsistencies in the form of cracks and shells in 52 pieces.

All detected on this verification stage incompatibilities were removed, however, the repair of the pipes caused the length to be lost. Therefore, 25 tubes were reclassified and went to the warehouse. Finishing and final treatments eliminated 50 pipes, of which 49 turned out to be too short and one scrapped. From the quantity of 1,070 pieces of waste used for rolling pipes, a total of 168 pieces had imperfections, of which 79 were scrapped and 89 reclassified at various stages of production.

Figure 7 shows a graph of the revealed defects at various stages of the all stages of production cycle.

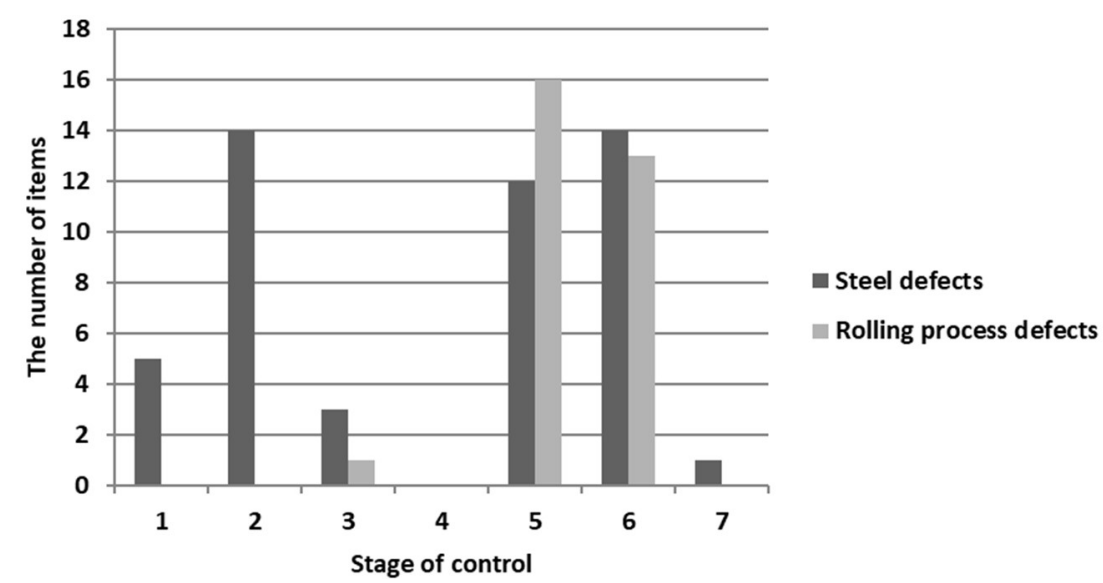

Fig. 7 Weight distribution due to source of origin

The analysis carried out showed that at the control stage:

1. the quality of the casts - all the defects were caused by steel defects, 
2. thimble-shaped hollows - all abrasions were caused by steel defects,

3. sleeves -3 abrasions were caused by steel and rolling process defects,

4. pipes - no defects were found after rolling,

5. pre-rolled pipes - 12 abrasions were caused by steelmaking defects, and 16 rolling process,

6. ultrasonic finished pipes -14 frets were caused by steelmaking defects and 13 rolling process,

7. the final one revealed a deficiency that was caused by a steel defect.

Out of all 79 defective pipes, 49 are steel defects that are detected at various stages of manufacture. The remaining ones 30 are defects resulting from the rolling process, verified during the inspection of rolled pipes.

Figure 8 shows the incompatibilities and defects found in the next stages of the inspection.

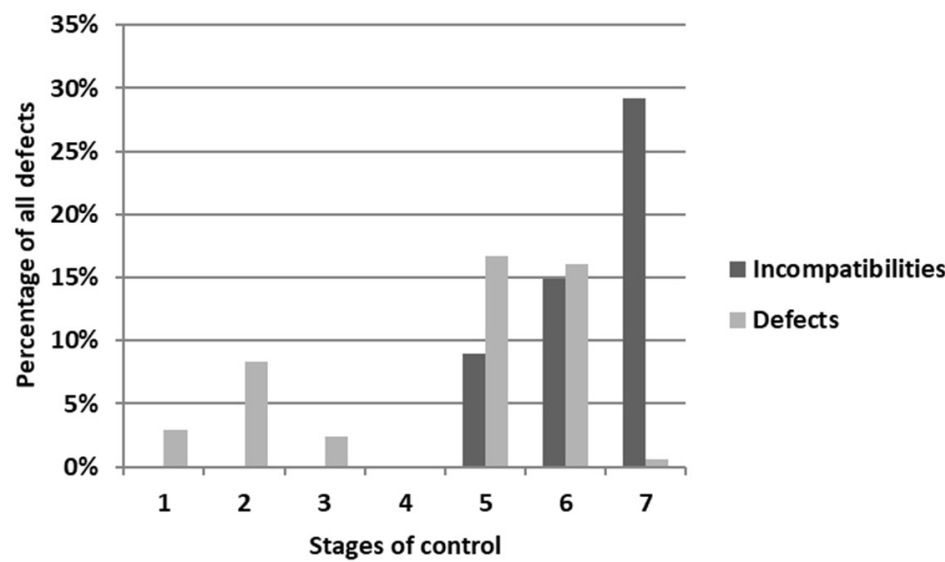

Fig. 8 Detected incompatibilities and defects at subsequent stages of control

168 pipes were reclassification and scrapped during the entire manufacturing process, of which at the control stage:

1. the quality of the charge -5 ingots were withdrawn from production, which accounted for almost $3 \%$ of all waste,

2. thimble-shaped hollows - after pressing defective there were 14 items, which constituted $8.33 \%$ of all defects,

3. sleeves - after breakthrough 4 defects were revealed, which constituted $2.38 \%$ of all defects

4. pipes - no defects were found after rolling,

5. pre-rolled pipes - (almost $9 \%$ ) and 28 defective pipes (16.67\% of all defects) were revealed,

6. ultrasonic finished pipes - 25 pipes with non-conformities (almost $15 \%$ of all defects) and 27 defective pipes (16.07\% of all defects),

7. the final -49 discrepancies $(29.17 \%$ of all defects) and 1 defective pipe $(0.6 \%$ of all defects)

The number of incompatibilities and defects revealed at various stages of production is shown in Figure 9. The chemical composition control showed that $100 \%$ of ingots were in line with the order, however, the quality control of the 
stock revealed 35 ingots with uncertainties, of which 5 were considered defective.

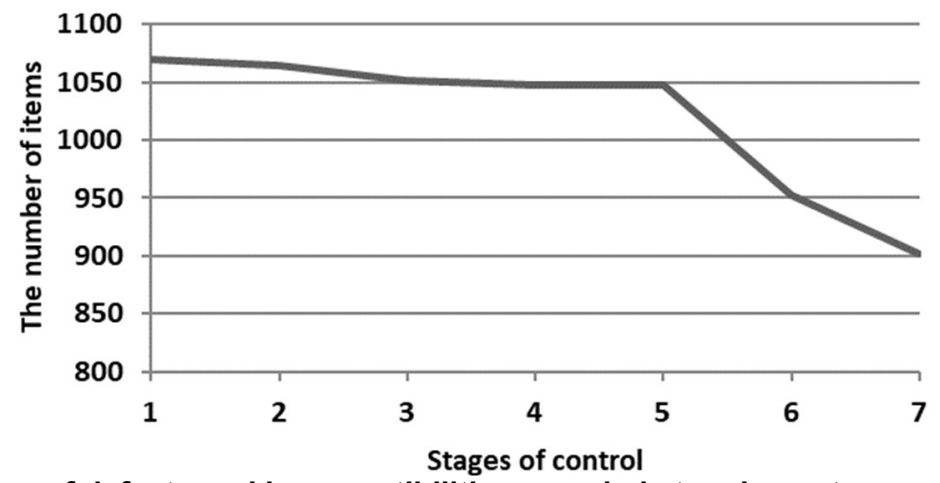

Fig. 9 Number of defects and incompatibilities revealed at various stages of production

After the heating process in the rotary furnace no discrepancies or defects were found. The number of defective ingots with steel defects excluded from production after the piercing process amounted to 14. Another 4 items were withdrawn from production due to defects revealed after rolling in a rolling mill. The initial acceptance after heat treatment and calibration reduced the number of tubes produced by 43 pieces, of which 15 were reclassified and 28 were scrapped. The next stage of the inspection revealed discrepancies in the form of cracks and shells on 322 pieces. All nonconformities were removed, however, the repair of the pipes caused the length to be lost. Therefore, 25 tubes were reclassified and went to the warehouse. Finishing and final treatments eliminated 50 pipes, of which 49 turned out to be too short and one was scrapped. From the quantity of 1070 pieces of used waste for rolling casing pipes, a total of 168 pieces were scrapped or reclassified at various stages of production.

\section{CONCLUSION}

Continuous development of market of seamless tube forces constant improvement of the products' quality. The improved production process should preserve the highest quality products, but also minimize production costs. Meeting these closely related conditions will result in a more efficient manufacturing process.

The analysis of the actual data recorded during the pipe manufacturing process made it possible to disclose, define and define incompatibilities and defects of metallurgical and technological origin at various stages of production. Discrepancies arising in the manufacturing process amount to $13.7 \%$, which is a very low percentage in relation to the entire production. By applying appropriate methods of eliminating imperfections, the process efficiency can be increased.

Reducing defects will result in a more efficient manufacturing process, increased product quality, and will strengthen the competitive position of the production 
company. Considering the constant increase in steel prices and cost of their production, this is an issue worth considering.

\section{REFERENCES}

Dobrzański L.A., Metaloznawstwo, WNT, Warszawa 1996

Dwivedi S., Rana R.S., Rana A., Rajpurohit S., Purohit R. (2017). Investigation of Damage in Small Deformation in Hot Rolling Process Using FEM, Material stoday Proceedings Volume 4, Issue 2, Part A, pp. 2360-2372

Gulajew A.P., Metaloznawstwo, Wydawnictwo Górniczo-Hutnicze, Katowice 1958

Hoderny B., Korek Z., Rury stalowe, Wydawnictwo „Śląsk”, Katowice 1976

Jiang Y., Tang H. (2015). Method for Improving Transverse Wall Thickness Precision of Seamless Steel Tube Based on Tube Rotation, Journal of Iron and Steel Research, International Volume 22, Issue 10, pp. 924-930

Kazanecki J., Wytwarzanie rur bez szwu, Uczelniane Wydaw. Nauk.-Dydakt. AGH im. S. Staszica, Kraków 2003

Knapiński M., Koczurkiewicz B., Dyja H., Kawałek A., Kwapisz M. (2013). Podstawowe badania eksperymentalnych stali dla rurociągów, Zjawiska stanu stałego, Mechatronic Systems and Materials V. Edited by Zdzisław Gosiewski, Zbigniew Kulesza, Vol.199, pp. 518-523

Kudliński Z., Technologie odlewania stali, Politechnika Śląska, Gliwice 2006

Luo Y. et al. (2014). Evolution of Surface Transversal Crack in Intermediate Slabsduring Hot Rolling Deformation, Journal of Iron and Steel Research, International Volume 21, Issue 4, pp. 476-480

Morioka N. et al. (1997). Development of manufacturing technology for high alloy steel samples pipe by Mannesmann process. „Kawasaki Steel”, t. 29, nr 2, pp. 57-63

Murcki C. O’Donnel R., Wady wyrobów walcowanych, Wydawnictwo GórniczoHutnicze, Katowice 1955

Nioi M. et al. (2017). Surface defect evolution in hot rolling of high-Si electrical steels, Journal of Materials Processing Technology Volume 249, pp. 302-312

Nioi M. et al. (2019). Finite element modelling of surface defect evolution during hot rolling of Silicon steel, Journal of Materials Processing Technology Volume 268, pp. 181-191

Norma API 5CT Spec Q1

Pavlov D., Erpalov M. (2019). Investigation of the influence of the frequency of rotation of the rolls on the inhomogeneity of deformation during lengthwise rolling of pipes on a stub mandrel, Materials today Proceedings, Available online July 2019

Penkała P., Proces walcowania skośnego w technologii wytwarzania rur bez szwu, Stal, Metale \& Nowe Technologie, Katowice 2017, nr 5-6, pp. 22-26,

Przybyłowicz K., Metaloznawstwo, Podręczniki akademickie - mechanika, WNT, Warszawa 1999

Shen J. et al. (2016). Analysis on the dynamic extension for transverse surface cracks in the as-cast steel slab at high temperatures, Engineering Failure Analysis Volume 66 , pp. 341-353

Utsunomiya H., Hara K., Matsumoto R., Azushima A. (2014). Formatiomechanism of surfaces Cale defects in hot rolling process, CIRP Annals Volume 63, Issue 1, pp. $261 \div 264$

Wang F. et al. (2014). Explorative study of tandem skew rolling process for producing seamless steel tubes, Journal of Materials Processing Technology Volume 214, Issue 8, pp. 1597-1604 


\begin{abstract}
.
The increase in the quality requirements for the pipes and the increasing needs to reduce production costs, while increasing the efficiency of the process in market of hot rolled pipes are observed. One of the cost reduction factors is the reduction of the number of defects by early detection and, if possible, the removal of non-conformities. Incompatibility is an error that can be removed in accordance with the performance standard that does not cause defects (Norma API). The defect is imperfection that is so important that it is the basis for the removal of the product or its part based on the criteria set out in the performance standards. In pipe manufacturing processes, defects and batch incompatibilities can be distinguished, which arise in the steelworks during metal solidification and roll forming in the course of metal processing. The defect may also arise as a result of removing steel material or result from rolling processes defects. The paper presents the analysis of the process of quality control of pipes manufactured using the pilgrim method on the basis of real process data. The analysis were involved 1070 pieces of ingots from 11 different melts for rolling pipes. At various stages of production, discrepancies and defects were revealed, which were caused by metallurgical or technological defects associated with rolling pipes. The total amount of discrepancies and defects eliminated 168 pieces of finished pipes. The aim of the work is to show that by means of appropriately selected methods of eliminating imperfections, it is possible to increase the efficiency of the manufacturing process.
\end{abstract}

Keywords: rolling process, pilgrim method, defects, seamless tube, pipe 